\title{
Lung cancer staging: a concise update
}

\author{
Ramón Rami-Porta ${ }^{1,2}$, Sergi Call ${ }^{1,3}{ }^{1,}$, Christophe Dooms ${ }^{4}$, Carme Obiols ${ }^{1}$, \\ Marcelo Sánchez ${ }^{5}$, William D. Travis ${ }^{6}$ and Ivan Vollmer ${ }^{5}$
}

Number 9 in the series "Multidisciplinary questions in thoracic oncology:
the team experience"
Edited by J-P. Sculier

\begin{abstract}
Affiliations: ${ }^{1}$ Dept of Thoracic Surgery, Hospital Universitari Mutua Terrassa, University of Barcelona, Barcelona, Spain. ${ }^{2}$ Network of Centres for Biomedical Research in Respiratory Diseases (CIBERES) Lung Cancer Group, Barcelona, Spain. ${ }^{3}$ Dept of Morphological Sciences, School of Medicine, Universitat Autònoma de Barcelona, Barcelona, Spain. ${ }^{4}$ Dept of Respiratory Diseases, University Hospitals, KU Leuven, Leuven, Belgium. ${ }^{5}$ Centre of Imaging Diagnosis, Radiology Dept, Hospital Clínic, University of Barcelona, Barcelona, Spain. ${ }^{6}$ Dept of Pathology, Memorial Sloan Kettering Cancer Center, New York, NY, USA.
\end{abstract}

Correspondence: Ramón Rami-Porta, Dept of Thoracic Surgery, Hospital Universitari Mútua Terrassa, Plaza Dr Robert 5, 08221 Terrassa, Barcelona, Spain. E-mail: rramiplayahoo.es

@ERSpublications

Lung cancer staging is a multidisciplinary activity that involves specialists in imaging, endoscopists, surgeons and pathologists at clinical and pathological staging http://ow.ly/z3M030jzmhN

Cite this article as: Rami-Porta R, Call S, Dooms C, et al. Lung cancer staging: a concise update. Eur Respir J 2018; 51: 1800190 [https://doi.org/10.1183/13993003.00190-2018].

ABSTRACT Diagnosis and clinical staging of lung cancer are fundamental to planning therapy. The techniques for clinical staging, i.e. anatomic and metabolic imaging, endoscopies and minimally invasive surgical procedures, should be performed sequentially and with an increasing degree of invasiveness. Intraoperative staging, assessing the magnitude of the primary tumour, the involved structures, and the loco-regional lymphatic spread by means of systematic nodal dissection, is essential in order to achieve a complete resection. In resected tumours, pathological staging, with the systematic study of the resected specimens, is the strongest prognostic indicator and is essential to make further decisions on therapy. In the present decade, the guidelines on lung cancer staging of the American College of Chest Physicians and the European Society of Thoracic Surgeons are based on the best available evidence and are widely followed. Recent advances in the classification of the adenocarcinoma of the lung, with the definition of adenocarcinoma in situ, minimally invasive adenocarcinoma and lepidic predominant adenocarcinoma, and the publication of the eighth edition of the tumour, node and metastasis classification of lung cancer, have to be integrated into the staging process. The present review complements the latest guidelines on lung cancer staging by providing an update of all these issues.

Previous articles in this series: No. 1: Malhotra J, Malvezzi M, Negri E, et al. Risk factors for lung cancer worldwide. Eur Respir J 2016; 48: 889-902. No. 2: McDonald F, De Waele M, Hendriks LEL, et al. Management of stage I and II nonsmall cell lung cancer. Eur Respir J 2017; 49: 1600764. No. 3: Leduc C, Antoni D, Charloux A, et al. Comorbidities in the management of patients with lung cancer. Eur Respir J 2017; 49: 1601721. No. 4: Zugazagoitia J, Molina-Pinelo S, Lopez-Rios F, et al. Biological therapies in nonsmall cell lung cancer. Eur Respir J 2017; 49: 1601520. No. 5: Calvayrac O, Pradines A, Pons E, et al. Molecular biomarkers for lung adenocarcinoma. Eur Respir J 2017; 49: 1601734. No. 6: Meert A-P, Grigoriu B, Licker M, et al. Intensive care in thoracic oncology. Eur Respir J 2017; 49: 1602189. No. 7: Glatzer M, Rittmeyer A, Müller J, et al. Treatment of limited disease small cell lung cancer: the multidisciplinary team. Eur Respir J 2017; 50: 1700422. No. 8: Peeters-Asdourian C, Massard G, Rana PH, et al. Pain control in thoracic oncology. Eur Respir J 2017; 50: 1700611.

Received: Jan 292018 | Accepted after revision: April 042018

Copyright @ERS 2018 


\section{Introduction}

The thoracic oncology community worldwide has never had such solid clinical practice guidelines on lung cancer staging as the ones provided by the American College of Chest Physicians and the European Society of Thoracic Surgeons (ESTS) in this decade [1-3]. Well-researched and profusely documented, these guidelines have set the pace of lung cancer staging in most parts of the world. They emphasise the importance of achieving the highest possible certainty at clinical and pathological staging by the thoughtful combination of imaging, endoscopies, minimally invasive surgical procedures, and thorough intraoperative staging, as well as by a sound pathological examination of tissue biopsies, fluids and resected specimens. Ideally the different tests available should be performed sequentially and with an increasing degree of invasiveness. Staging at the time of diagnosis is fundamental to planning initial therapy, and staging after tumour resection is the strongest prognostic indicator and provides information essential for making decisions on postoperative therapy.

In 2015, the new classification of adenocarcinoma of the lung, proposed by the International Association for the Study of Lung Cancer (IASLC), the American Thoracic Society and the European Respiratory Society in 2011 [4], was accepted by the World Health Organization and included in its most recent book on pathology of thoracic malignancies [5].

A year later, the eighth edition of the tumour, node and metastasis (TNM) classification was published jointly by the Union for International Cancer Control (UICC), the American Joint Committee on Cancer and the IASLC [6-8]. The new primary tumour categories based on tumour size [9]; the coding for adenocarcinoma in situ (AIS) and minimally invasive adenocarcinoma (MIA), and the recommendation on how to measure tumour size [10]; the reclassification of some $\mathrm{T}$ descriptors [9]; the relevance of quantifying nodal disease [11]; the subclassification of extrathoracic metastases [12]; and the rearrangement of stage groupings [13] have staging and clinical implications that will have to be addressed by all those involved in the management of lung cancer patients (tables 1 and 2).

It is in the context of these events that this concise review, authored by an international and multidisciplinary team of professionals deeply involved in lung cancer staging, is offered with the objective to update relevant issues that complement the published guidelines.

\section{Imaging techniques}

Radiology and nuclear medicine play an important role in the clinical staging of lung cancer. After a proper medical history and physical examination, chest radiography usually is the first step in the study of many thoracic diseases [14], but contrast-enhanced spiral computed tomography (CT) is the technique of choice in the study of lung cancer [15]. CT should examine the chest and the upper abdomen. Chest radiography is useful for the assessment of the postoperative course on a day-to-day basis, and for postoperative follow-up, as a baseline to compare with subsequent radiographic studies. Positron emission tomography (PET) imaging, and especially the integrated PET-CT technique, have changed the staging of lung cancer, and should be routinely performed for optimal clinical staging. Other techniques, such as transthoracic ultrasounds or magnetic resonance imaging (MRI), play a secondary role with specific indications.

\section{The T component}

CT remains the best technique in the clinical measurement of tumour size [16]. The size of the tumour is one of the most important prognostic factors in lung cancer. In the eighth edition of the TNM classification, it proved to be more relevant than in the previous editions, because it can separate tumours of significantly different survival at $1 \mathrm{~cm}$ intervals from less than $1 \mathrm{~cm}$ to $5 \mathrm{~cm}$ in greatest dimension [9]. In clinical staging, tumour size should be measured with inspiratory CT using the lung window, and the longest diameter in any projection should be reported [10]. In cases of part-solid pulmonary nodules with ground glass opacity, the size of the solid component is the one to be used to assign a clinical T category based on size [10]. It is also recommended to register the total size (solid and ground glass components) to evaluate its prognostic implications, because presence of a ground glass component has a favourable prognosis [17]. The CT findings of ground glass and solid opacities in non-mucinous adenocarcinomas tend to correspond with lepidid and invasive histopathological patterns, respectively. These radiographic findings suggest the diagnosis of AIS, MIA or lepidid predominant adenocarcinomas (LPA), but the correlation is not absolute and should be regarded as a preliminary assessment subject to revision after histopathological evaluation of the resected specimens [10].

In general, CT depicts the invasion of the great vessels or mediastinal structures, but other techniques are useful in specific settings. Transthoracic ultrasound and MRI offer better results than CT in the evaluation of parietal pleural and chest wall invasion $[18,19]$. For pre-operative staging of Pancoast tumours MRI 
TABLE 1 Main innovations in the eighth edition of the TNM classification of lung cancer

\section{T descriptors}

Adenocarcinoma in situ

Minimally invasive adenocarcinoma

Tumour $\leqslant 1 \mathrm{~cm}$

Tumour $>1 \mathrm{~cm}$ but $\leqslant 2 \mathrm{~cm}$ in greatest dimension

Tumour $>2 \mathrm{~cm}$ but $\leqslant 3 \mathrm{~cm}$ in greatest dimension

Tumour $>3 \mathrm{~cm}$ but $\leqslant 4 \mathrm{~cm}$ in greatest dimension

Tumour $>4 \mathrm{~cm}$ but $\leqslant 5 \mathrm{~cm}$ in greatest dimension

Tumour $>5 \mathrm{~cm}$ but $\leqslant 7 \mathrm{~cm}$ in greatest dimension

Tumour $>7 \mathrm{~cm}$ in greatest dimension

Endobronchial location any distance from the main carina but with no invasion of the carina

Total (whole lung) atelectasis or pneumonitis

Invasion of diaphragm

Invasion of mediastinal pleura

\section{$\mathbf{N}$ descriptors}

Involvement of one N1 nodal station

Involvement of multiple N1 nodal stations

Involvement of one N2 nodal station without N1

Involvement of multiple N2 nodal stations with N1

Involvement of multiple N2 nodal stations

\section{M descriptors}

Single extrathoracic metastasis"

Multiple extrathoracic metastases in one or in several organs ${ }^{\#}$

\section{Measurement of tumour size}

On computed tomography

Of part-solid tumours on computed tomography

Of part-solid non-mucinous adenocarcinoma at pathological examination

After induction therapy

Tis (AIS)
T1mi
T1a
T1b
T1c
T2a
T2b
T3
T4
T2
T2
T4
Disappears $a$ descriptor
N1a
N1b
N2a1
N2a2
N2b
M1b
M1c

Use the lung window in the projection that provides the greatest dimension

Use size of solid component to assign a T category based on tumour size

Use size of invasive component to assign a T category based on tumour size

Multiply the percentage of viable tumour cells by the size of the total mass

\#: this includes the involvement of non-regional lymph nodes.

showed better results than CT [20]. Transthoracic ultrasound, MRI and PET-CT might be of added value in the differentiation between lung cancer and obstructive atelectasis [16].

\section{The $\mathrm{N}$ component}

In 2009, the IASLC proposed a new chart of the regional lymph nodes, grouped in zones and stations [21] that has to be considered carefully in the staging of lung cancer [22]. A survey by EL-SHERIEF et al. [23] demonstrated that the use of older maps and the inconsistencies in interpretation and application of the definitions of the IASLC lymph node map may potentially lead to stage misclassification and suboptimal management of lung cancer in some patients. Classically, lymph nodes with a short axis over $10 \mathrm{~mm}$ measured by CT are considered abnormal. This classical criterion has little diagnostic accuracy [24]. In the diagnosis of nodal involvement, SHIM et al. [25] demonstrated a sensitivity of 0.70 for CT and of 0.85 for PET-CT. In addition, Prenzel et al. [26] showed that $77 \%$ of patients without nodal involvement had nodes $>1 \mathrm{~cm}$ in short axis, and that $12 \%$ of patients with $\mathrm{N} 1$ or $\mathrm{N} 2$ tumours did not present any node with a short axis $>1 \mathrm{~cm}$. PET-CT shows better results than CT alone and PET alone in the diagnosis of lymph node involvement [24-28]. Still, the sensitivity of PET-CT is related to the size of the nodes, with a sensitivity of 0.85 for nodes greater than or equal to $10 \mathrm{~mm}$, but of only 0.32 for nodes less than $10 \mathrm{~mm}$ in diameter [29].

Diffusion-weighted MRI has a potential role to differentiate benign from malignant lymph nodes [30]. A meta-analysis performed by Wu et al. [31] demonstrated that diffusion MRI has equal sensitivity than PET-CT (0.75 versus 0.72, respectively), but higher specificity (PET-CT 0.89 versus MRI 0.95). However, two clinical trials did not find differences in the diagnostic value of PET-CT and diffusion MRI for staging lung cancer $[32,33]$. Diffusion-weighted MRI could be considered in some cases as an alternative to 


\begin{tabular}{|c|c|c|c|}
\hline Stage & $T$ & $\mathbf{N}$ & M \\
\hline Occult carcinoma & $\mathrm{TX}$ & No & MO \\
\hline 0 & Tis & NO & MO \\
\hline \multirow[t]{2}{*}{ IA1 } & T1mi & NO & MO \\
\hline & $\mathrm{T} 1 \mathrm{a}$ & NO & MO \\
\hline IA2 & $\mathrm{T} 1 \mathrm{~b}$ & No & MO \\
\hline IA3 & T1c & No & MO \\
\hline IB & T2a & No & MO \\
\hline IIA & $\mathrm{T} 2 \mathrm{~b}$ & NO & MO \\
\hline \multirow[t]{3}{*}{ IIB } & T1a, b, c & N1 & MO \\
\hline & $\mathrm{T} 2 \mathrm{a}, \mathrm{b}$ & N1 & MO \\
\hline & T3 & No & MO \\
\hline \multirow[t]{5}{*}{ IIIA } & $\mathrm{T} 1 \mathrm{a}, \mathrm{b}, \mathrm{c}$ & N2 & MO \\
\hline & $\mathrm{T} 2 \mathrm{a}, \mathrm{b}$ & N2 & MO \\
\hline & T3 & N1 & MO \\
\hline & T4 & No & MO \\
\hline & T4 & N1 & MO \\
\hline \multirow[t]{4}{*}{ IIIB } & $\mathrm{T} 1 \mathrm{a}, \mathrm{b}, \mathrm{c}$ & N3 & MO \\
\hline & $\mathrm{T} 2 \mathrm{a}, \mathrm{b}$ & N3 & MO \\
\hline & T3 & N2 & MO \\
\hline & $\mathrm{T} 4$ & N2 & MO \\
\hline \multirow[t]{2}{*}{ IIIC } & T3 & N3 & MO \\
\hline & T4 & N3 & MO \\
\hline \multirow[t]{2}{*}{ IVA } & Any $T$ & Any $\mathrm{N}$ & M1a \\
\hline & Any $T$ & Any $\mathrm{N}$ & M1b \\
\hline IVB & Any $T$ & Any $\mathrm{N}$ & M1c \\
\hline
\end{tabular}

Reproduced and adapted with permission from [13].

PET-CT [34], but more studies are needed to establish the role of MRI in the study of the $\mathrm{N}$ descriptors in lung cancer.

\section{The M component}

Lung cancer metastases can be intra- or extrathoracic. Lung metastases can be identified on CT. The eighth edition of the TNM classification provides recommendations on how to differentiate separate tumour nodules from multifocal adenocarcinomas at clinical and pathological staging $[35,36]$. CT can identify pleural metastasis as pleural nodules, and PET-CT can show pleural uptake of FDG [16]. Extrathoracic metastases can be depicted easily with PET-CT. One of the important contributions of PET-CT for lung cancer staging is the detection of unrecognised metastases and upstaging of tumours [37]. Adrenal metastases can be correctly depicted by PET-CT [38, 39], and no other techniques are needed. In a systematic review and meta-analysis of published data, PET alone showed a sensitivity of 0.97 and a specificity of 0.91 , with a false-positive rate of $9.7 \%$, due to some benign adrenal lesions that showed mild FDG uptake [40]. Therefore, isolated positive adrenal lesions should be confirmed in order to avoid deeming a patient inoperable on a false-positive basis [37]. Cerebral staging is recommended in all patients with curative therapeutic options [41, 42]. MRI shows better results than CT in the diagnosis of brain metastases [43]. Deuschl et al. [44] evaluated PET-MRI performed in lung cancer staging, concluding that PET-MRI did not show any improvement in cerebral staging of these patients, as MRI alone remains the gold standard. Nevertheless, brain imaging is not necessary in the staging of pure ground glass nodular lung adenocarcinoma [45]. Bone metastases can be detected with PET-CT, PET-MRI and diffusion sequence in MRI [37].

Globally, PET-CT is the best tool in the initial staging of lung cancer, even in the study of small cell lung cancer [46], compared with CT, bone scan and bone marrow analysis [16, 47], except for brain metastases.

\section{New techniques}

PET-MRI is a promising hybrid technique combining anatomy and functional imaging. UsUDA et al. [48] did not find significant differences in accuracy between staging tumours with PET-CT plus brain MRI and whole-body diffusion-weighted MRI, and concluded that they were equivalent in the staging of clinically resectable lung cancer. Combining PET-MRI with or without contrast-enhanced CT is comparable to 
PET-CT in the preoperative staging of lung cancer $[49,50]$, with a reduction of $31 \%$ of the radiation dose [50]. Another study comparing coregistered whole-body MRI-PET with PET-CT plus brain MRI found that both staging protocols had greater than 20\% correct upstaging compared to conventional staging methods, but MRI-PET was not superior to PET-CT plus brain MRI [51].

New radiotracers, such as ${ }^{18}$ F-fluorothymide, ${ }^{11} \mathrm{C}$-methionine, ${ }^{18} \mathrm{~F}$-fluoromisonidazole, and ${ }^{68} \mathrm{Ga}$-DOTA-peptides, have been used in a research environment but could have an important role in the next few years in the era of personalised therapy for patients with lung cancer [52]. In fact, ${ }^{68} \mathrm{Ga}$-DOTA-peptide scan already is part of the standard staging work-up in cases of FDG-negative (a)typical carcinoid. In a study of 53 patients, ${ }^{18} \mathrm{~F}-\mathrm{NaF}$ PET showed no false-negatives in the detection of bone metastases, while bone scan and SPECT had six and one false-negatives, respectively [53]. Also, ${ }^{18} \mathrm{~F}-\mathrm{NaF}$ PET impacted the clinical management in $11 \%$ of the patients [53].

\section{Endoscopic techniques}

\section{Standard flexible videobronchoscopy for lung cancer staging}

White light flexible videobronchoscopy permits endobronchial staging of the primary tumour in addition to pathological confirmation. A flexible bronchoscopy can determine the endobronchial extension of the primary tumour (T1a, radio-occult superficial spreading tumour of any size with its invasive component limited to the bronchial wall which may extend proximal into the main bronchus; T1, tumour $\leqslant 3 \mathrm{~cm}$ not extending into main bronchus; T2, tumour involving main bronchus distal to main carina; T4, tumour involving main carina and/or distal trachea), or can detect synchronous radio-occult endobronchial lesions [9]. In addition, a conventional transbronchial needle aspiration can be performed during the initial flexible bronchoscopy if enlarged mediastinal lymph nodes are present on computed tomography of the chest. In clinical N2 disease with a prevalence of $\mathrm{N} 2 / \mathrm{N} 3$ disease of $>80 \%$ the technique has a variable sensitivity of $0.15-0.83$ to detect nodal disease and a false-negative rate of $28 \%$, mostly related to the size and location of the nodes and the operators' experience $[54,55]$. Nevertheless, as demonstrated within a randomised controlled trial, a conventional transbronchial needle aspiration (TBNA) performed during a first standard bronchoscopy can be a valuable mediastinal staging tool in clearly enlarged (defined as $>15 \mathrm{~mm}$ in largest short axis) nodes in stations $4 \mathrm{R}$ (right inferior paratracheal), 7 (subcarinal) and 4L (left inferior paratracheal), or for unresectable bulky mediastinal nodal infiltration when a pathological diagnosis is lacking [56].

\section{Linear endosonography for mediastinal lymph node staging in non-small cell lung cancer}

When mediastinal nodal staging by linear endobronchial ultrasonography with transbronchial needle aspiration (EBUS-TBNA) is required, systematic nodal sampling seems feasible but some primary choices have to be made. At least mediastinal nodal stations $4 \mathrm{R}$ (right inferior paratracheal), 4L (left inferior paratracheal) and 7 (subcarinal) should be sought. All FDG-PET positive node(s) or the largest node $\geqslant 5 \mathrm{~mm}$ in each nodal station should be biopsied. It is possible to visualise and sample lymph nodes with a short axis of $\geqslant 5 \mathrm{~mm}$ and the optimal number of aspirations per station for nodal staging has been reported to be three $[57,58]$. To avoid contamination, the order of sampling should begin at the level of N3 stations followed by N2 stations before N1 stations.

EBUS allows the exploration of mediastinal lymph node stations 2R (right superior paratracheal), 2L (left superior paratracheal), 3p (retrotracheal), 4L (left inferior paratracheal), 4R (right inferior paratracheal) and 7 (subcarinal). It must be stressed that EBUS cannot access the prevascular nodes (station 3a), the subaortic and para-aortic nodes (stations 5 and 6), or the para-oesophageal and pulmonary ligament nodes (stations 8 and 9). Some of these nodes (stations 8 and 9) can, however, be reached from the oesophagus. Several authors have therefore extended the use of the EBUS scope to an oesophageal exploration (EUS-B) of stations 4L (left inferior paratracheal), 7 (subcarinal), 8 (para-oesophageal) and 9 (pulmonary ligament) [59, 60].

Linear endosonography is a safe procedure with a low complication rate of $1-2 \%$ and reported mortality of $0.01 \%[61,62]$.

\section{Endosonography for mediastinal/hilar nodal staging in early stage non-small cell lung cancer} In patients with tumours classified as clinical N0 at PET-CT, recent studies reported a risk of mediastinal nodal involvement of $<20 \%$ and sensitivity of $0.17-0.41$ for EBUS-TBNA to detect mediastinal nodal disease [63-66]. Two prospective multicentre studies reported a risk of mediastinal nodal involvement of $25 \%$ in 205 patients classified as clinical N1 at PET-CT $[67,68]$. In resectable patients classified as clinical $\mathrm{N} 1$ at PET-CT, a sensitivity of $0.38-0.53$ has been reported for endosonography to detect mediastinal nodal disease $[66,67,69]$. 
Overall, the routine use of a preoperative EBUS-TBNA for systematic mediastinal nodal sampling in clinical stage I-IIB non-small cell lung cancer has only a moderate sensitivity to detect mediastinal nodal disease and does not greatly increase the negative predictive value of PET-CT [63-68]. In the concepts of Bayesian decision analysis, given a pre-test prevalence of $10-25 \%$ and sensitivity for EBUS-TBNA of less than $50 \%$ to detect mediastinal nodal disease in early stage non-small cell lung cancer, a post-test probability of greater than $10 \%$ is expected requiring another invasive staging test, taking into account the testing decision threshold of $10 \%$ required by the ESTS guidelines [2]. Therefore, the routine use of EBUS-TBNA for mediastinal nodal staging in clinical stage I-IIB lung cancer should not be offered, but a mediastinoscopy may represent the preferred approach in invasive mediastinal nodal staging in these patients.

It should be acknowledged, however, that EBUS-TBNA can accurately assess the hilar and interlobar lymph nodes in clinical N1 disease with a sensitivity and negative predictive value of 0.76 and 0.96 , respectively [69]. The latter is relevant to non-surgical patients considered for stereotactic body or conformal radiotherapy.

\section{Endosonography for mediastinal nodal staging in locally advanced non-small cell lung cancer} A risk of mediastinal nodal involvement of at least $60 \%$ has been reported in patients with tumours classified as clinical N2/3 at PET-CT. The two staging strategies proposed in the 2007 ESTS guidelines, surgical staging alone on the one hand and endosonography followed by surgical staging whenever endosonography was negative on the other hand, were compared in a pivotal randomised controlled trial $[70,71]$. It was concluded that invasive mediastinal nodal staging should start with endosonography, as the trial showed that a staging strategy starting with combined linear endosonography detected significantly $(\mathrm{p}=0.02)$ more mediastinal nodal disease compared to cervical mediastinoscopy alone, resulting in a significantly higher sensitivity of 0.94 (95\% CI $0.85-0.98$ ) compared to 0.79 (95\% CI $0.66-0.88$ ), respectively [71]. A subgroup analysis of patients with clinical N2/3 at PET-CT demonstrated a sensitivity for endosonography of 0.86 to detect $\mathrm{N} 2 / 3$ disease, which increased to 0.97 when surgical staging was added after a negative endosonography [72]. Another randomised controlled trial comparing EBUS-TBNA with cervical mediastinoscopy in a patient group with 59\% mediastinal nodal disease demonstrated a sensitivity of 0.88 (95\% CI $0.78-0.94)$ and 0.81 (95\% CI $0.70-0.89)$, respectively, confirming endosonography to be the first choice in invasive mediastinal staging for clinical N2/3 lung cancer [73]. Given a post-test probability after a negative test of $>0.10$ for endosonography in a context of high index of suspicion for mediastinal nodal disease, a confirmatory cervical mediastinoscopy is warranted as this lowers the post-test probability to $<0.05$ [2, 72-74]. In case of a positive result by EBUS-EUS demonstrating N2 disease, mediastinoscopy can be performed after induction therapy to evaluate tumour response and decide on further treatment. This strategy yields the highest sensitivity and accuracy in restaging after induction therapy [75].

\section{Combined endobronchial and oesophageal endosonography}

There has been no randomised controlled trial comparing combined EBUS and EUS-B to EBUS-TBNA alone for mediastinal nodal staging, but a recent meta-analysis assessed the accuracy and the added value of the combined use of endobronchial and oesophageal endosonography for mediastinal nodal staging in lung cancer [74]. The mean sensitivity and negative predictive value of the combined approach in studies that relied on a reference standard with low risk of bias were 0.83 (95\% CI $0.77-0.87$ ) and 0.91 (95\% CI 0.86-0.95), respectively [74]. The addition of EUS(-B) to EBUS led to a mean increase in sensitivity of 0.12 (95\% CI $0.08-0.18$ ) and to a mean increase in detection rate of 0.04 (95\% CI 0.03-0.06), which implies a number needed to test of 25 (95\% CI 17-33) to detect one additional patient with mediastinal nodal metastases that would be missed if only EBUS-TBNA had been done [74]. Although not yet widely adopted, combined EBUS and EUS-B can be done both with the EBUS scope in conjunction in a single session by a single endoscopist. This strategy facilitates the combined endobronchial and oesophageal endosonography approach as this is quicker, more comfortable for patients and cost-effective compared to using two scopes by two endoscopists, reducing the need for surgical staging procedures [74-77].

\section{Imaging guided (ultrasound/CT) transthoracic techniques}

\section{Transthoracic needle aspiration and transthoracic needle core biopsy}

Transthoracic needle aspiration (TTNA) is usually performed to obtain tissue diagnosis of parenchymal nodules or masses. For this indication, an accuracy of 0.9 has been described, although it may decrease depending on the location, depth and size of nodules [78]. As a staging procedure, it can be useful in patients with contralateral nodules to confirm metastatic disease. For mediastinal staging, TTNA can be used when there is bulky mediastinal disease, to diagnose and certify its extension. In this situation, a sensibility of 0.94 has been reported, with an average prevalence of mediastinal cancer $>80 \%$. For the 
diagnosis of peripheral lung lesions, transthoracic needle core biopsy (TNCB) compared with TTNA has similar sensitivity for malignancy but a better ability to determine a specific diagnosis for nonmalignant lesions. The main advantage of TNCBs is that they result in a higher yield of tissue specimens for mutation analysis [79]. Complication rate of both techniques is low, being the pneumothorax the most frequent $(7-10 \%)[1,79,80]$.

\section{Thoracocentesis}

Patients with suspected lung cancer presenting with pleural effusion should undergo thoracocentesis with cyto-pathological analysis. Confirmation of malignant pleural effusion (MPE) is a sign of intrathoracic dissemination, defining an M1a category [12]. More than $90 \%$ of MPE are exudates and half of them haemorrhagic. Diagnostic yield ranges from $61 \%$ to $90 \%[79,81,82]$. When two consecutive cytological examinations are negative, a video-assisted thoracoscopic surgery (VATS) is recommended due to its sensitivity $>0.90$ and low rate of complications $[79,81,83]$.

\section{Preoperative minimally invasive surgical staging techniques \\ Video-assisted thoracoscopic surgery}

VATS allows the assessment of the $\mathrm{T}$, the $\mathrm{N}$ and the $\mathrm{M}$ descriptors. Regarding those patients with lung cancer and several nodules in the same or contralateral lung, VATS can diagnose synchronous lung cancer versus T3 (separate tumour nodule(s) in the same lobe), T4 (separate tumour nodule(s) in a different ipsilateral lobe), or M1a (separate tumour nodule(s) in contralateral lung) [9, 12, 84]. Small nodules, especially those not involving the pleural surface, and subsolid ground glass opacities may be difficult to localise by VATS. Several techniques have been developed to facilitate their intraoperative detection [85]. When applying these targeting methods, the success rate of identifying nodules by VATS ranges from 96 to $99 \%$ [86].

The suspicion of pleural or pericardial effusion (M1a) can be pathologically confirmed by this technique, achieving a definitive diagnosis rate in $90-95 \%$ of cases. Moreover, chemical pleurodesis or pericardial window can be performed in the same procedure [80, 87-89].

VATS for mediastinal staging allows the assessment of ipsilateral lymph nodes. Regarding left-sided tumours, the aorto-pulmonary window lymph nodes can be easily explored; however, left paratracheal nodes usually remain unexplored due to their difficult access. Staging values of VATS show a sensitivity ranging from $0.58-1$ (median 0.99 ) (table 3 ) and a false-negative rate of $4 \%$. Average complication rate for this indication is $2 \%[1,90-92]$.

TABLE 3 Accuracy of video-assisted thoracic surgery (VATS), videomediastinoscopy (VAM) and extended cervical mediastinoscopy (ECM) for surgical staging of the mediastinum in patients with lung cancer

\begin{tabular}{|c|c|c|c|c|c|c|c|c|}
\hline Author & Year & Patients $\mathrm{n}$ & Prevalence \% & Sensitivity & Specificity & PPV & NPV & Lymph node reached \\
\hline \multicolumn{9}{|l|}{ VATS } \\
\hline Cerfolio [90] & 2007 & 39 & 92 & 1 & 1 & 1 & 1 & Left side: $5,6,7,8 \mathrm{~L}, 9 \mathrm{~L}$ \\
\hline Sebastian-QuetLAs [92] & 2003 & 79 & 24 & 0.58 & 1 & 1 & 0.88 & \\
\hline \multicolumn{9}{|l|}{ VAM } \\
\hline DeCLauwé [68]" & 2017 & 105 & 26 & 0.73 & 1 & 1 & 0.92 & $2 \mathrm{R}, 2 \mathrm{~L}, 4 \mathrm{R}, 4 \mathrm{~L}, 7,8 \mathrm{R}, 8 \mathrm{~L}$ \\
\hline ANRAKu [103] & 2010 & 89 & 22 & 0.95 & 1 & 1 & 0.99 & \\
\hline LESCHBER [104] & 2008 & 119 & 17 & NA & 1 & NA & 0.83 & \\
\hline KIMURA [105] & 2007 & 209 & 31 & 0.78 & 1 & 1 & 0.91 & \\
\hline LARDINOIS [75] & 2003 & 195 & 34 & 0.87 & 1 & 1 & 0.92 & \\
\hline VeNISSAC [106] & 2003 & 154 & 71 & 0.97 & 1 & 1 & 0.94 & \\
\hline \multicolumn{9}{|l|}{ ECM } \\
\hline GINSBERG [111] & 1987 & 100 & 29 & 0.71 & 1 & 1 & 0.89 & \\
\hline
\end{tabular}

PPV: positive predictive value; NPV: negative predictive value; NA: not available. ${ }^{\#}$ : the authors report 997 conventional mediastinoscopies and 243 VAM. Staging values were calculated based on the total number. "?: study in the context of clinical N1 disease. 
Finally, VATS has also been described as an exploratory procedure to evaluate resectability and staging in order to decide proceeding to pulmonary resection in the same surgical act [93].

\section{Pericardioscopy}

In patients with pericardial effusion but without pleural effusion, there is no need to access the pericardium through the pleural space. In these cases, a subxyphoid approach provides access to the pericardium. It can be incised and the fluid drained. An endoscope, usually a mediastinoscope [94, 95] or a flexible endoscope [96], can be inserted to explore the inner surface of the pericardium and the epicardium. Biopsies can be taken and, if malignancy is proved, instillation of chemical agents for pericardiodesis can be done at the end of the procedure [96]. Pericardioscopy can also be useful to assess resectability of hilar tumours with suspicion of intrapericardial extension [97]. Sensitivity of pericardioscopy can be as high as 0.97 . Complication rate is $6.1 \%$, arrhythmias being the most frequent. Postoperative mortality of $3.5 \%$ has been reported, but it is important to consider that this procedure is usually performed in fragile patients with an advanced cancer [93, 95-99].

\section{Mediastinoscopy and its variants}

Based on the current North American and European guidelines for preoperative mediastinal nodal staging for lung cancer $[1,2]$, invasive methods are recommended to obtain tissue confirmation of regional nodal spread except in patients with small $(\leqslant 3 \mathrm{~cm})$ peripheral carcinomas with no evidence of nodal involvement on CT and PET. Minimally invasive endoscopic techniques (EBUS-TBNA and EUS-FNA or their combination) are included in the staging algorithms as the first invasive technique, when they are available. However, their negative results should be validated by surgical methods. To date, mediastinoscopy remains the gold standard in the staging process. It provides reliable information on the mediastinal nodal status and/or direct mediastinal invasion of the primary tumour.

Mediastinoscopy allows the exploration of the superior and middle mediastinum through a cervical incision. The use of a videomediastinoscope (VAM) over a standard mediastinoscope improves the visualisation of the operative field, which may increase accuracy and facilitate the teaching process $[1,100]$. The nodal stations that can be reached are: right and left superior and inferior paratracheal $(2 \mathrm{R}, 2 \mathrm{~L}, 4 \mathrm{R}$, $4 \mathrm{~L})$, subcarinal (7), right and left para-oesophageal (8R, 8L) and right and left hilar (10R, 10L) stations. According to European and North American guidelines, ideally, stations 2R, 2L, 4R, 4L and 7 should be examined routinely $[1,2]$. Staging values described for VAM are: sensitivity ranging from 0.78 to 0.97 , and negative predictive value ranging from 0.83 to 0.99 (table 3). Complication rate is $2 \%$, temporal left recurrent laryngeal nerve palsy being the most frequent [1, 101-106].

Anterior mediastinotomy (the classic Chamberlain procedure) consists of a left parasternal incision at the level of the second or third intercostal space, to access the aortopulmonary window lymph nodes. The median sensitivity and negative predictive values reported are 0.71 and 0.91 , respectively [1].

Extended cervical mediastinoscopy allows the assessment of subaortic (5) and para-aortic (6) stations from the same cervical incision used in the VAM. The exploration starts with a VAM, which rules out mediastinal involvement in paratracheal and subcarinal stations. A median sensitivity of 0.71 and negative predictive value of 0.91 have been described (table 3). Complication rate ranges from 0 to $7.2 \%$, although the majority of them are not specific to extended cervical mediastinoscopy [1, 107-111].

Mediastino-thoracoscopy achieves the assessment of the mediastinum and pleural cavity using the transcervical approach [112]. At the time of mediastinoscopy, the mediastinal pleura can be opened and the pleural space, explored. The following procedures can be performed through this approach: aspiration of pleural fluid, pleural biopsies, resection of pulmonary nodules and/or instillation of pleurodesis agents. A pathological diagnosis is obtained in $78 \%$ of malignant lesions. Reported complication rate ranges between $0.7-10 \%$, being the left recurrent laryngeal nerve palsy the most frequent [112].

\section{Transcervical lymphadenectomies}

Two new surgical staging procedures have been recently developed: video-assisted mediastinoscopic lymphadenectomy (VAMLA) and transcervical extended mediastinal lymphadenectomy (TEMLA). In comparison with mediastinoscopy, in which only biopsy samples from lymph nodes are taken, these techniques achieve a complete clearance of all the lymph node stations explored, allowing the identification of minimal nodal disease that is not identified on CT or PET. The main difference between these procedures is that VAMLA is an endoscopic technique performed through a videomediastinoscope, and TEMLA is an open procedure assisted by a videomediastinoscope or a videothoracoscope, depending on the nodal station dissected. Due to their high diagnostic accuracy (table 4), VAMLA and TEMLA are especially indicated in those situations of intermediate probability of finding N2 disease: central tumours, clinical N1 tumours and tumour size $>3 \mathrm{~cm}$. Regarding complications, published series describe a 
TABLE 4 Accuracy of transcervical lymphadenectomies for surgical staging of the mediastinum in patients with lung cancer

\begin{tabular}{lcccccccc} 
Author & Year & Patients n & Prevalence \% & Sensitivity & Specificity & PPV & NPV & Lymph node reached \\
\hline VAMLA & & & & & & & & $2 \mathrm{R}, 2 \mathrm{~L}, 4 \mathrm{R}, 4 \mathrm{~L}, 7,8 \mathrm{R}, 8 \mathrm{~L}$ \\
$\quad$ CALL [113] & 2016 & 151 & 18 & 0.96 & 1 & 1 & 0.99 & \\
$\quad$ TURNA [114] & 2013 & 89 & 44 & 0.95 & 1 & 1 & 0.94 & \\
$\quad$ WITTE [115] & 2006 & 144 & 12 & 0.88 & 1 & 1 & 0.98 & \\
$\begin{array}{l}\text { TEMLA } \\
\quad \text { ZIELINSKI [116] }\end{array}$ & 2014 & 928 & 25 & 0.96 & 1 & 1 & 0.98 & $1,2 \mathrm{R}, 2 \mathrm{~L}, 4 \mathrm{R}, 4 \mathrm{~L}, 7,8,3 \mathrm{a}, 3 \mathrm{p}, 5,6$ \\
\hline
\end{tabular}

PPV: positive predictive value; NPV: negative predictive value; VAMLA: video-assisted mediastinoscopic lymphadenectomy; TEMLA: transcervical extended mediastinal lymphadenectomy.

morbidity rate ranging from $4 \%$ to $9 \%$ for VAMLA and $6.6 \%$ for TEMLA. The most common complication for both procedures is recurrent laryngeal nerve palsy. Other infrequent complications are: pleural effusion managed with conservative treatment (1.6\% for TEMLA), pneumothorax $(0.4 \%$ for TEMLA, $0.5 \%$ for VAMLA), and postoperative bleeding requiring revision $(0.2 \%$ for TEMLA, $0.5 \%$ for VAMLA). Regarding mortality, there was no mortality after VAMLA, and $5(0.7 \%)$ patients died after TEMLA, but their deaths were unrelated to the procedure [113-117].

\section{Intrathoracic staging at pulmonary resection}

Whether lung resection is attempted by the classic thoracotomy approach or by any of the varieties (multiportal, uniportal, robotic) of VATS, it must ensure that the primary tumour is completely removed or that, if resection is not possible, adequate biopsies are taken to evaluate the highest pathological ( $p$ ) $\mathrm{T}$ category [118]. During the operation, the primary tumour must not be transgressed and the adjacent or invaded structures, such as the chest wall, the diaphragm or the neighbouring lobe, must be resected en bloc to avoid spillage of cancer cells into the operative field [119]. If pleural effusion is identified on opening the chest, a sample should be taken for cytological analysis. Its positivity would classify the tumour as M1a. In case of diffuse pleural spread, lung resection will not improve prognosis.

Resection of the primary tumour must be accompanied by an adequate lymph node evaluation to validate the absence of nodal disease ( $\mathrm{pN} 0$ ) or certify the highest $\mathrm{pN}$ category [118]. How to perform this intraoperative nodal evaluation has been a matter of debate for decades. In 1997, the term systematic nodal dissection was proposed to describe the removal of mediastinal and hilar-pulmonary lymph nodes [120]. The mediastinal part of systematic nodal dissection has two standards: the en bloc removal of the fatty tissue and lymph nodes of the ipsilateral mediastinum or the removal of three lymph nodes from three nodal stations, always including the subcarinal nodes. This manoeuvre is followed by the dissection of the hilar and intrapulmonary lymph nodes. An acceptable intraoperative nodal evaluation must include, at least, six lymph nodes, three from the mediastinum, including the subcarinal, and three from the hilar and intrapulmonary nodal stations. This minimum requirement is incorporated in the definition of $\mathrm{pN} 0$ proposed by the UICC [121]. The location of the mediastinal lymph nodes to be removed was further defined when the IASLC proposed its definitions of complete resection, for which an adequate nodal evaluation is fundamental. The required evaluation of mediastinal lymph nodes, when an en bloc resection is not performed, depends on the lobar location of the primary tumour $[122,123]$. For the right upper and middle lobes, the nodal stations to explore are the subcarinal and one of the following: superior and inferior paratracheal nodes and the pretracheal nodes, now included in the right paratracheal, according the lymph node map proposed by the IASLC [21]. For the right lower lobe, subcarinal and right inferior paratracheal, and either the para-oesophageal or the pulmonary ligament nodes. For the left upper lobe, subcarinal, subaortic and anterior mediastinal nodes. For the left lower lobe, subcarinal, para-oesophageal and pulmonary ligament nodes. This type of evaluation was called lobe-specific systematic nodal dissection, but, strictly speaking, it is a systematic sampling [124]. If this minimal requirement of intraoperative nodal assessment were not met, the IASLC proposed to call the resection uncertain. If macroscopic or microscopic tumour was left in the operative field, the resection would be incomplete, regardless of the nodal evaluation. The definitions proposed by the IASLC have been validated. There are significant differences in survival when complete, uncertain and incomplete resections are compared, which proved their clinical relevance in the staging and treatment of lung cancer [125].

The scenario in 1997 was quite different from the one we are experiencing now, two decades later, when videothoracoscopic resections are becoming the standard of care [126]. This change in surgical approach has raised three questions concerning the feasibility of systematic nodal dissection by videothoracoscopic approach, 
the prognostic impact of systematic nodal dissection and sampling, and their complications. Regarding the feasibility of systematic nodal dissection performed by videothoracoscopy, recent reports show that it can be performed whether videothoracoscopy is performed with three, two or one ports, or with a robot [127-131].

The impact on survival of systematic nodal dissection and sampling still is controversial. A randomised trial comparing sampling and complete mediastinal lymphadenectomy for clinical T1-T2 N0 and non-hilar N1 revealed no differences in 5-year disease-free survival rates or in local, regional and distant recurrence [132]. However, in those patients undergoing complete lymphadenectomy, a median number of 18 nodes (range 1-72 for right-sided tumours and 4-69 for left-sided tumours) were additionally removed after sampling, and 21(4\%) patients were found to have occult N2 disease [133]. A report on lobe-specific systematic nodal dissection found that, although there were no statistically significant differences when survival was compared with that of systematic nodal dissection, mediastinal nodal recurrence was significantly higher in the group of patients who underwent lobe-specific systematic nodal dissection [134]. Considering that the number of removed lymph nodes has prognostic impact even in patients with pN0 tumours, and that quantification of nodal disease based on the number of involved nodal zones [135], on the number of involved nodal stations [11] or on the lymph node ratio, that is the number of involved lymph nodes divided by the number of removed lymph nodes [136], also has prognostic implications, complete lymphadenectomy has clear advantages for the individual patient, although these advantages remain occult when series of patients are analysed. In addition, systematic nodal dissection is not associated with higher complication rates when compared to sampling [137, 138]. It is also important to realise that the concept of lobe-specific systematic nodal dissection is based on statistics, on the probability of nodal involvement depending on the lobar location of the tumour, but it is not exact [139-141]. Involved lymph nodes may remain beyond the nodal stations explored, and their presence has a deleterious effect on prognosis [142]. Lobe-specific systematic nodal dissection certainly is better than no nodal dissection at all, but systematic nodal dissection is the only procedure that ensures an accurate staging and the probability of prolonged survival for the individual patient.

Pleural lavage cytology before and after resection is a cheap and rapid method for refining intraoperative staging and postoperative prognosis. It is positive in between 3 and $7 \%$ of patients, even in those with stage I adenocarcinoma. A positive pleural lavage is consistently associated with higher rates of recurrence and lower survival in reported series [143-150] and in meta-analyses [151-153]. It has been suggested to increase the $\mathrm{T}$ category of those tumours with positive pleural lavage cytology, but it already has a code in the TNM staging system: R1 (cy+). Therefore, it should be considered a microscopic incomplete resection.

\section{Pathological issues in TNM staging}

In the eighth edition of the TNM classification of lung cancer there are several important changes involving pathology issues. These include the introduction of concepts of AIS, MIA and LPA, as well as the usefulness of histological comparison of multiple lung adenocarcinomas using the tool of comprehensive histological subtyping [4, 5, 10, 80, 154]. In addition, pathological issues related to determining the extent of tumour invasion of anatomic sites such as the visceral pleura remain the same as in previous staging classifications [155].

Addition of Tis (AIS) for adenocarcinoma in situ and T1mi for minimally invasive adenocarcinoma It was recommended to add AIS to the category of Tis, which previously consisted only of squamous cell carcinoma in situ (SCIS). So now, AIS is coded as Tis (AIS) in distinction from Tis (SCIS) [6, 8, 10]. AIS is defined as a localised small $(\leqslant 3 \mathrm{~cm})$ adenocarcinoma with tumour cells growing along pre-existing alveolar walls in a lepidic pattern where invasion of stroma, vessels, alveolar spaces or visceral pleura are lacking (table 5). In addition, invasive adenocarcinoma patterns such as solid, acinar, papillary or micropapillary patterns are absent. Spread through air spaces (STAS), consisting of tumour cells appearing within air spaces in the lung parenchyma beyond the edge of the main tumour, should be absent. AIS can have either a non-mucinous, mucinous or mixed mucinous and non-mucinous histology, but most cases of AIS are non-mucinous, consisting of type II pneumocytes and/or club (formerly Clara) cells $[4,5]$. The diagnosis of both AIS and MIA requires complete histological sampling.

Cases of adenocarcinoma with a pure lepidic pattern larger than $3.0 \mathrm{~cm}$ are extremely rare and not well documented in the literature. Therefore, there is insufficient data to know their clinical behaviour and it is recommended to classify such tumours as LPA and to assign a pathological Tla category. If the entire tumour has been processed for histological examination and no invasion is identified, the possibility of AIS can be mentioned in a comment $[4,5]$.

It was also recommended to classify MIA as T1mi $[6,8,10]$. MIA is defined as a small $(\leqslant 3 \mathrm{~cm})$, solitary adenocarcinoma, with a lepidic predominant pattern and invasion measuring $\leqslant 5 \mathrm{~mm}$ (table 5) $[4,5]$. The invasive area should be measured in the largest dimension $[4,5]$. In some cases the invasive component 
TABLE 5 Pathological criteria for adenocarcinoma in situ (AIS) and minimally invasive adenocarcinoma

Adenocarcinoma in situ

A small tumour $\leqslant 3 \mathrm{~cm}$

A solitary adenocarcinoma\#

Pure lepidic growth

No stromal, vascular or pleural invasion

No pattern of invasive adenocarcinoma (such as acinar, papillary, micropapillary, solid, colloid, enteric, fetal or invasive mucinous adenocarcinoma)

No STAS

Cell type mostly non-mucinous (type II pneumocytes or Clara (club) cells), but rarely may be mucinous (tall columnar cells with basal nuclei and abundant cytoplasmic mucin, sometimes resembling goblet cells)

Nuclear atypia is absent or inconspicuous

Septal widening with sclerosis/elastosis is common, particularly in non-mucinous adenocarcinoma in situ

\section{Minimally invasive adenocarcinoma}

Modified from references $[4,5]$. STAS: spread through air spaces. ${ }^{\#}$ : when multiple AIS are found, they should be regarded as separate primaries rather than intrapulmonary metastases.

represents a single focus that can be measured grossly or in some cases, where the entire tumour fits on a single H\&E slide, it can be measured microscopically with a ruler. When invasion consists of multiple foci, or the invasive focus does not fit on a single slide, it can be impossible to measure with a ruler on the microscopic slide. In such cases it is proposed to estimate the invasive size by multiplying the total percentage of invasive components determined by comprehensive histological subtyping by the total tumour size. For example in a $1.5 \mathrm{~cm}$ tumour with $20 \%$ invasive histological components (acinar, papillary, micropapillary or solid) the invasive size would be estimated at $0.3 \mathrm{~cm}[10,156]$. Most MIA are non-mucinous but rare cases of mucinous or mixed mucinous and non-mucinous MIA occur $[4,5,10,157]$. The lepidic component of non-mucinous type of MIA consists of a proliferation of atypical type II pneumocytes and/or club (formerly Clara) cells along the alveolar walls. The mucinous type of MIA consists of columnar cells with abundant apical mucin and small basally oriented nuclei that may show goblet cell features.

In MIA, the invasive component can be identified in the following way: 1) non-lepidic histological subtypes such as acinar, papillary, micropapillary and/or solid or 2) infiltration of myofibroblastic stroma. The diagnosis of MIA is excluded if the tumour 1) invades lymphatics, blood vessels, alveolar spaces or pleura, 2) exhibits tumour necrosis, or 3) shows STAS $[4,5]$. In tumours where the invasive component is greater than $0.5 \mathrm{~cm}$, the diagnosis should be lepidic predominant adenocarcinoma. In addition, if the total size is larger than $3.0 \mathrm{~cm}$, the tumour is best classified as lepidic predominant adenocarcinoma and pathological T1a. A recent study suggests that rare cases, otherwise fitting criteria for MIA, that have a total size larger than $3.0 \mathrm{~cm}$ may be classified as MIA. In this study the maximum tumour size was $4.7 \mathrm{~cm}$ [158]. However, this proposal needs more validation.

\section{Use invasive size for $T$ categories based on size in non-mucinous lung adenocarcinoma with a lepidic pattern}

The invasive size is now recommended for the determination of the $\mathrm{T}$ category based on tumour size in lung non-mucinous adenocarcinomas with a lepidic component. The lepidic component is excluded from the measurement. The same principles in measurement mentioned in MIA apply for these tumours as well. So, in addition to documenting the total tumour size (i.e. the maximum measurement of the ground glass or lepidic component), the invasive component needs to be documented and this is what is used for the size of the $\mathrm{T}$ category. This principle does not apply to invasive mucinous adenocarcinomas for which the total tumour size is used to determine the T category [10].

Adenocarcinomas with predominant lepidic growth, if they have an invasive component larger than $0.5 \mathrm{~cm}$, are classified as lepidic predominant adenocarcinoma. 


\section{Visceral pleural invasion}

Pathological involvement of the visceral pleura by lung cancer is classified at three levels of invasion including into the pleura beyond the main elastic layer (PL1), to the visceral pleural surface (PL2) and into the chest wall (PL3) [155]. When the tumour does not reach the elastic layer, it is classified as PL0 and this feature is not used as a T descriptor; when PL1 or PL2, it is T2; and when PL3, it is T3. Analysis of the IASLC database in preparation for revisions for the eighth edition of the TNM classification confirmed the worse prognosis for PL1 and PL2, but it also showed that PL2 had a significantly worse prognosis compared to PL1 [9]. In cases where the relationship to the pleura is not clear, elastic stains may be very helpful in clarifying whether the tumour invades into the visceral pleura.

\section{Conclusion}

Clinical and pathological staging of lung cancer by means of a thoughtful combination of imaging and metabolic techniques, endoscopies, minimally invasive surgical interventions, detailed resection, and systematic pathological examination provide the greatest certainty to indicate initial therapy, assign prognosis before and after treatment, and make further therapeutic decisions after tumour resection. The existing clinical practice guidelines and the innovations in pathological and anatomic classifications of lung cancer, as well as in the imaging procedures, endoscopies and surgical procedures, increase the precision and the thoroughness of the staging process and, thus, assist the clinician in the management of lung cancer patients.

Conflict of interest: None declared.

\section{References}

1 Silvestri GA, Gonzalez AV, Jantz MA, et al. Methods for staging non-small cell lung cancer: Diagnosis and management of lung cancer, 3rd ed: American College of Chest Physicians evidence-based clinical practice guidelines. Chest 2013; 143: e211S-e250S.

2 De Leyn P, Dooms C, Kuzdzal J, et al. Revised ESTS guidelines for preoperative mediastinal lymph node staging for non-small-cell lung cancer. Eur J Cardiothorac Surg 2014; 45: 787-798.

3 Lardinois D, De Leyn P, Van Schil P, et al. ESTS guidelines for intraoperative lymph node staging in non-small cell lung cancer. Eur J Cardiothorac Surg 2006; 30: 787-792.

4 Travis WD, Brambilla E, Noguchi M, et al. The New IASLC/ATS/ERS international multidisciplinary lung adenocarcinoma classification. J Thorac Oncol 2011; 6: 244-285.

5 Travis WD, Brambilla E, Burke AP, et al. WHO Classification of Tumours of the Lung, Pleura, Thymus and Heart. Lyon, International Agency for Research on Cancer, 2015.

6 Brierley JD, Gospodarowicz MK, Wittekind Ch, eds. UICC TNM Classification of Malignant Tumours. 8th Edn. Oxford, Wiley Blackwell, 2017.

Amin MB, ed. AJCC Cancer Staging Manual. 8th Edn. Springer, 2017.

Rami-Porta R, ed. IASLC Staging Manual in Thoracic Oncology. North Fort Myers, Editorial Rx Press, 2016.

Rami-Porta R, Bolejack V, Crowley J, et al. The IASLC Lung Cancer Staging Project: proposals for the revisions of the $\mathrm{T}$ descriptors in the forthcoming 8th edition of the TNM classification for lung cancer. $J$ Thorac Oncol 2015; 10: 990-1003.

10 Travis WD, Asamura H, Bankier A, et al. The IASLC Lung Cancer Staging Project: proposals for coding T categories for subsolid nodules and assessment of tumor size in part-solid tumors in the forthcoming eighth edition of the TNM classification of lung cancer. J Thorac Oncol 2016; 11: 1204-1223.

11 Asamura H, Chansky K, Crowley J, et al. The IASLC Lung Cancer Staging Project: proposals for the revisions of the $\mathrm{N}$ descriptors in the forthcoming 8th edition of the TNM classification for lung cancer. J Thorac Oncol 2015; 10: $1675-1684$.

12 Eberhardt WEE, Mitchell A, Crowley J, et al. The IASLC Lung Cancer Staging Project: proposals for the revisions of the $\mathrm{M}$ descriptors in the forthcoming 8th edition of the TNM classification for lung cancer. $J$ Thorac Oncol 2015; 10: 1515-1522.

13 Goldstraw P, Chansky K, Crowley J, et al. The IASLC Lung Cancer Staging Project: proposals for the revision of the stage grouping in the forthcoming (8th) edition of the TNM classification of lung cancer. J Thorac Oncol 2016; 11: 39-51.

14 Kirsch J, Ramirez J, Mohammed TL, et al. ACR Appropriateness Criteria: acute respiratory illness in immunocompetent patients. J Thorac Imaging 2011; 26: W42-W44.

15 de Castro J, Cobo M, Isla D, et al. Recommendations for radiological diagnosis and assessment of treatment response in lung cancer: a national consensus statement by the Spanish Society of Medical Radiology and the Spanish Society of Medical Oncology. Clin Transl Oncol 2015; 17: 11-23.

16 Kitajima K, Doi H, Kanda T, et al. Present and future roles of FDG-PET/CT imaging in the management of lung cancer. Jpn J Radiol 2016; 34: 387-399.

17 Hattori A, Matsunaga T, Takamochi K, et al. Importance of ground glass opacity component in clinical stage IA radiologic invasive lung cancer. Ann Thorac Surg 2017; 104: 313-320.

18 Kajiwara N, Akata S, Uchida O, et al. Cine MRI enables better therapeutic planning than CT in cases of possible lung cancer chest wall invasion. Lung Cancer 2010; 69: 203-208.

19 Bandi V, Lunn W, Ernst A, et al. Ultrasound vs. CT in detecting chest wall invasion by tumor: a prospective study. Chest 2008; 133: 881-886.

20 Bruzzi JF, Komaki R, Walsh GL, et al. Imaging of non-small cell lung cancer of the superior sulcus: part 2: initial staging and assessment of resectability and therapeutic response. Radiographics 2008; 28: 561-572. 

J Thorac Oncol 2009; 4: 568-577.

22 El-Sherief AH, Lau CT, Wu CC, et al. International association for the study of lung cancer (IASLC) lymph node map: radiologic review with CT illustration. Radiographics 2014; 34: 1680-1691.

23 El-Sherief AH, Lau CT, Obuchowski NA, et al. Cross-disciplinary analysis of lymph node classification in lung cancer on computed tomography. Chest 2017; 151: 776-785.

24 Gelberg J, Grondin S, Tremblay A. Mediastinal staging for lung cancer. Can Respir J 2014; 21: $159-161$.

25 Shim SS, Lee KS, Kim BT, et al. Non-small cell lung cancer: prospective comparison of integrated FDG PET-CT and CT alone for preoperative staging. Radiology 2005; 236: 1011-1019.

26 Prenzel KL, Mönig SP, Sinning JM, et al. Lymph node size and metastatic infiltration in non-small cell lung cancer. Chest 2003; 123: 463-467.

27 Gould MK, Kuschner WG, Rydzak CE, et al. Test performance of positron emission tomography and computed tomography for mediastinal staging in patients with non-small-cell lung cancer: a meta-analysis. Ann Intern Med 2003; 139: 879-892.

28 Zhao L, He ZY, Zhong XN, et al. 18FDG-PET/CT for detection of mediastinal nodal metastasis in non-small cell lung cancer: a meta-analysis. Surg Oncol 2012; 21: 230-236.

29 Lv YL, Yuan DM, Wang K, et al. Diagnostic performance of integrated positron emission tomography/computed tomography for mediastinal lymph node staging in non-small cell lung cancer: a bivariate systematic review and meta-analysis. J Thorac Oncol 2011; 6: 1350-1358.

30 Malayeri AA, el Khouli RH, Zaheer A, et al. Principles and applications of diffusion-weighted imaging in cancer detection, staging, and treatment follow-up. Radiographics 2011; 31: 1773-1791.

$31 \mathrm{Wu} \mathrm{LM}, \mathrm{Xu} \mathrm{JR}, \mathrm{Gu} \mathrm{HY}$, et al. Preoperative mediastinal and hilar nodal staging with diffusion-weighted magnetic resonance imaging and fluorodeoxyglucose positron emission tomography/computed tomography in patients with non-small-cell lung cancer: which is better? J Surg Res 2012; 178: 304-314.

32 Pauls S, Schmidt SA, Juchems MS, et al. Diffusion-weighted MR imaging in comparison to integrated [ $\left.{ }^{18} \mathrm{~F}\right]-\mathrm{FDG}$ PET/CT for N-staging in patients with lung cancer. Eur J Radiol 2012; 81: 178-182.

33 Sommer G, Wiese M, Winter L, et al. Preoperative staging of non-small-cell lung cancer: comparison of whole-body diffusion-weighted magnetic resonance imaging and 18F-fluorodeoxyglucose-positron emission tomography/computed tomography. Eur Radiol 2012; 22: 2859-2867.

34 Shen G, Lan Y, Zhang K, et al. Comparison of 18F-FDG PET/CT and DWI for detection of mediastinal nodal metastasis on non-small cell lung cancer: A meta-analysis. PLoS One 2017; 12: e0173104.

35 Detterbeck FC, Marom EM, Arenberg DA, et al. The IASLC Lung Cancer Staging Project: background data and proposals for the application of TNM staging rules to lung cancer presenting as multiple nodules with ground glass or lepidic features or a pneumonic type of involvement in the forthcoming eighth edition of the TNM classification. J Thorac Oncol 2016; 11: 666-680.

36 Detterbeck FC, Bolejack V, Arenberg DA, et al. The IASLC Lung Cancer Staging Project: background data and proposals for the classification of lung cancer with separate tumor nodules in the forthcoming eighth edition of the TNM classification for lung cancer. J Thorac Oncol 2016; 11: 681-692.

37 Harders SW, Balyanikowa S, Fischer BM. Functional imaging in lung cancer. Clin Physiol Funct Imaging 2014; 34: 340-355.

38 Metser U, Miller E, Lerman H, et al. 18F-FDG PET/CT in the evaluation of adrenal masses. J Nucl Med 2006; 47: $32-37$.

39 Ozcan Kara P, Kara T, Kara Gedik G, et al. The role of fluorodeoxyglucose-positron emission tomography/ computed tomography in differentiating between benign and malignant adrenal lesions. Nucl Med Commun 2011; 32: 106-112.

40 Boland GW, Dwamena BA, Jagtiani Sangwaiya M, et al. Characterization of adrenal masses by using FDG PET: a systematic review and meta-analysis of diagnostic test performance. Radiology 2011; 259: 117-126.

41 O’Dowd EL, Kumaran M, Anwar S, et al. Brain metastases following radical surgical treatment of non-small cell lung cancer: is preoperative brain imaging important? Lung Cancer 2014; 86: 185-189.

42 Detterbeck FC, Postmus PE, Tanoue LT. The stage classification of lung cancer: Diagnosis and management of lung cancer, 3rd ed: American College of Chest Physicians evidence-based clinical practice guidelines. Chest 2013; 143: e191S-e210S.

43 Millon D, Byl D, Collard P, et al. Could new reconstruction CT techniques challenge MRI for the detection of brain metastases in the context of initial lung cancer staging? Eur Radiol 2018; 28: 770-779.

44 Deuschl C, Nensa F, Grueneisen J, et al. Diagnostic impact of integrated 18F-FDG PET/MRI in cerebral staging of patients with non-small cell lung cancer. Acta Radiol 2017; 58: 991-996.

45 Cho H, Lee HY, Kim J, et al. Pure ground glass nodular adenocarcinomas: are preoperative positron emission tomography/computed tomography and brain magnetic resonance imaging useful or necessary? J Thorac Cardiovasc Surg 2015; 150: 514-520.

46 Mitchell MD, Aggarwal C, Tsou AY, et al. Imaging for the pretreatment staging of small cell lung cancer: a systematic review. Acad Radiol 2016; 23: 1047-1056.

47 Fischer BM, Mortensen J, Langer SW, et al. A prospective study of PET/CT in initial staging of small-cell lung cancer: comparison with CT, bone scintigraphy and bone marrow analysis. Ann Oncol 2007; 18: 338-345.

48 Usuda K, Sagawa M, Maeda S, et al. Diagnostic performance of whole-body diffusion-weighted imaging compared to PET-TC plus brain-MRI in staging clinically resectable lung cancer. Asian Pac J Cancer Prev 2016; 17: 2775-2780.

49 Schaarschmidt BM, Grueneisen J, Metzenmacher M, et al. Thoracic staging with 18F-FDG PET/MR in non-small cell lung cancer - does it change therapeutic decisions i comparison to 18F-FDG PET/CT? Eur Radiol 2017; 27: 681-688.

50 Lee SM, Goo JM, Park CM, et al. Preoperative staging of non-small cell lung cancer: prospective comparison of PET/MR and PET/CT. Eur Radiol 2016; 26: 3850-3857. 

tomography (MRI-PET) versus PET-computed tomography plus brain MRI in staging resectable lung cancer. Comparison of clinical effectiveness in a randomized trial. Cancer 2013; 119: 1784-1791. Szyszko TA, Yip C, Szlosarek P, et al. The role of new PET tracers for lung cancer. Lung Cancer 2016; 94: 7-14.

53 Schirrmeister H, Glatting G, Hetzel J, et al. Prospective evaluation of the clinical value of planar bone scans, SPECT, and (18F)-labeled NaF PET in newly diagnosed lung cancer. J Nucl Med 2011; 42: 1800-1804.

54 Holty J, Kuschner W, Gould M. Accuracy of transbronchial needle aspiration for mediastinal staging of non-small cell lung cancer: a meta-analysis. Thorax 2005; 60: 949-955.

55 Fiorelli A, Santoriello C, Di Natale D, et al. In the era of ultrasound technology, could conventional transbronchial needle aspiration still play a role in lung cancer mediastinal staging? J Thorac Dis 2017; 9: Suppl. 5, S386-S394.

56 Bonifazi M, Tramacere I, Zuccatosta L, et al. Conventional versus ultrasound-guided transbronchial needle aspiration for the diagnosis of hilar/mediastinal lymph adenopathies: a randomized controlled trial. Respiration 2017; 94: 216-223.

57 Lee HS, Lee GK, Lee HS, et al. Real-time endobronchial ultrasound-guided transbronchial needle aspiration in mediastinal staging of non-small cell lung cancer: how many aspirations per target lymph node station? Chest 2008; 134: 368-374.

58 Yasufuku K, Pierre A, Darling G, et al. A prospective controlled trial of endobronchial ultrasound-guided transbronchial needle aspiration compared with mediastinoscopy for mediastinal lymph node staging of lung cancer. J Thorac Cardiovasc Surg 2011; 142: 1393-1400.

59 Hwangbo B, Lee GK, Lee HS, et al. Transbronchial and transesophageal fine-needle aspiration using an ultrasound bronchoscope in mediastinal staging of potentially operable lung cancer. Chest 2010; 138: 795-802

60 Oki M, Saka H, Ando M, et al. Endoscopic ultrasound-guided fine needle aspiration and endobronchia ultrasound-guided transbronchial needle aspiration: are two better than one in mediastinal staging of non-small cell lung cancer? J Thorac Cardiovasc Surg 2014; 148: 1169-1177.

61 von Bartheld MB, van Breda A, Annema JT. Complication rate of endosonography (endobronchial and endoscopic ultrasound): a systematic review. Respiration 2014; 87: 343-351.

62 Yarmus L, Akulian J, Gilbert C, et al. Comparison of moderate versus deep sedation for endobronchial ultrasound transbronchial needle aspiration. Ann Am Thorac Soc 2013; 10: 121-126.

63 Shingyoji M, Nakajima T, Yoshino M, et al. Endobronchial ultrasonography for positron emission tomography and computed tomography-negative lymph node staging in non-small cell lung cancer. Ann Thorac Surg 2014; 98: $1762-1767$.

64 Ong P, Grosu H, Eapen GA, et al. Endobronchial ultrasound-guided transbronchial needle aspiration for systematic nodal staging of lung cancer in patients with N0 disease by computed tomography and integrated positron emission tomography-computed tomography. Ann Am Thorac Soc 2015; 12: 415-419.

65 Vial M, O’Connell O, Grosu H, et al. Diagnostic performance of endobronchial ultrasound-guided mediastinal lymph node sampling in early stage non-small cell lung cancer: a prospective study. Respirology 2018; 23: 76-81.

66 Naur T, Konge L, Clementsen P. Endobronchial ultrasound-guided transbronchial needle aspiration for staging of patients with non-small cell lung cancer without mediastinal nodal involvement at positron emission tomography-computed tomography. Respiration 2017; 94: 279-284.

67 Dooms C, Tournoy KG, Schuurbiers O, et al. Endosonography for mediastinal nodal staging of clinical N1 non-small cell lung cancer: a prospective multicenter study. Chest 2015; 147: 209-2015.

68 Decaluwé $\mathrm{H}$, Dooms C, D’Journo XB, et al. Mediastinal staging by videomediastinoscopy in clinical N1 non-small cell lung cancer: a prospective multicentre study. Eur Respir J 2017; 50: 1701493.

69 Yasufuku K, Nakajima T, Waddell T, et al. Endobronchial ultrasound-guided transbronchial needle aspiration for differentiating N0 versus N1 lung cancer. Ann Thorac Surg 2013; 96: 1756-1760.

70 De Leyn P, Lardinois D, Van Schil PE, et al. ESTS guidelines for preoperative lymph node staging for non-small cell lung cancer. Eur J Cardiothorac Surg 2007; 32: 1-8.

71 Annema JT, van Meerbeeck JP, Rintoul RC, et al. Mediastinoscopy vs endosonography for mediastinal nodal staging of lung cancer: a randomized trial. JAMA 2010; 304: 2245-2252.

72 Tournoy K, Keller S, Annema J. Mediastinal staging of lung cancer: novel concepts. Lancet Oncol 2012; 13: e221-e229.

73 Um S, Kim H, Jung S, et al. Endobronchial ultrasound versus mediastinoscopy for mediastinal nodal staging of non-small cell lung cancer. J Thorac Oncol 2015; 10: 331-337.

74 Korevaar D, Crombag L, Cohen J, et al. Added value of combined endobronchial and oesophageal endosconography for mediastinal nodal staging in lung cancer: a systematic review and meta-analysis. Lancet Respir Med 2016; 4: 960-968.

75 Lardinois D, Schallberger A, Betticher D, et al. Postinduction video-mediastinoscopy is as accurate and safe as video-mediastinoscopy in patients without pretreatment for potentially operable non-small cell lung cancer. Ann Thorac Surg 2003; 75: 1102-1106.

76 Kang H, Hwangbo B, Lee GK, et al. EBUS-centered versus EUS-centered mediastinal staging in lung cancer: a randomised controlled trial. Thorax 2014; 69: 261-268.

77 Oki M, Saka H, Ando M, et al. Transbronchial versus transesophageal needle aspiration using an ultrasound bronchoscope for the diagnosis of mediastinal lesions: a randomised study. Chest 2015; 147: 1259-1266.

78 Yang W, Jiang H, Khan AN, et al. Transthoracic needle aspiration in solitary pulmonary nodule. Transl Lung Cancer Res 2017; 6: 76-85.

79 Rivera MP, Mehta AC. Establishing the diagnosis of lung cancer: diagnosis and management of lung cancer, 3rd ed: ACCP evidence-based clinical practice guidelines. Chest 2013; 143: e142S-e165S.

80 De Margerie-Mellon C, de Bazelaire C, Amorim S, et al. Diagnostic yield and safety of computed tomography-guided mediastinal core needle biopsies. J Thorac Imaging 2015; 30: 319-327.

81 Zarogoulidis C, Zarogoulidis $\mathrm{P}$, Darwiche $\mathrm{K}$, et al. Malignant pleural effusion and algorithm management. J Thorac Dis 2013; 5: S413-S419.

82 Assawasaksakul T, Boonsarngsuk V, Incharoen P. A comparative study of conventional cytology and cell block method in the diagnosis of pleural effusion. J Thorac Dis 2017; 9: 3161-3167. 
Wang XJ, Yang Y, Wang Z, et al. Efficacy and safety of diagnostic thoracoscopy in undiagnosed pleural effusions. Respiration 2015; 90: 251-255.

Detterbeck FC, Nicholson AG, Franklin WA, et al. The IASLC Lung Cancer Staging Project: summary of proposals for revisions of the classification of lung cancers with multiple pulmonary sites of involvement in the forthcoming eight edition of the TNM classification. J Thorac Oncol 2016; 11: 639-650.

Lin MW, Chen JS. Image-guided techniques for localizing pulmonary nodules in thoracoscopic surgery. $J$ Thorac Dis 2016; 8: S749-S755.

Park $\mathrm{CH}$, Han K, Hur J, et al. Comparative effectiveness and safety of preoperative lung localization of pulmonary nodules: a systematic review and meta-analysis. Chest 2017; 151: 316-328.

Celik M, Halezeroglu S, Senol C, et al. Video-assisted thoracoscopic surgery: experience with 341 cases. Eur J Cardiotrhorac Surg 1998; 14: 113-116.

Krasna MJ. The role of thoracoscopy in the management of cancer patients. Semin Oncol 2008; 35: $129-133$.

Mizukami Y, Ueda N, Adachi H, et al. Long-term outcomes after video-assisted thoracoscopic pericardiectomy for pericardial effusion. Ann Thorac Cardiovasc Surg 2017; 23: 304-308. lymph nodes in patients with non-small cell lung cancer. Ann Thorac Surg 2007; 84: 940-945.

Massone PP, Lequaglie C, Magnani B, et al. The real impact and usefulness of video-assisted thoracoscopic surgery in the diagnostic and therapy of clinical lymphadenopathies of the mediastinum. Ann Surg Oncol 2003; 10: $1197-1202$.

Sebastián-Quetglás F, Molins L, Baldó X, et al. Clinical value of video-assisted thoracoscopy for preoperative staging of non-small cell lung cancer. A prospective study of 105 patients. Lung Cancer 2003; 42: 297-301.

Loscertales J, Jimenez-Merchan R, Congregado M, et al. Video-assisted surgery for lung cancer. State of the art and personal experience. Asian Cardiovasc Thorac Ann 2009; 17: 313-326.

Porte HL, Janecki-Delebecq TJ, Finzi L, et al. Pericardioscopy for primary management of pericardial effusion in cancer patients. Eur J Cardiothorac Surg 1999; 16: 287-291.

Little AG, Ferguson MK. Pericardioscopy as adjunct to pericardial window. Chest 1986; 89: 53-55.

Maisch B, Ristic A, Pankuweit S. Evaluation and management of pericardial effusion in patients with neoplastic disease. Prog Cardiovasc Dis 2010; 53: 157-163.

Kondos GT, Rich S, Levitsky S. Flexible fiberoptic pericardioscopy for the diagnosis of pericardial disease. $J A m$ Coll Cardiol 1986; 7: 432-434.

Saab J, Hoda RS, Narula N, et al. Diagnostic yield of cytopathology in evaluating pericardial effusions: clinicopathologic analysis of 419 specimens. Cancer Cytopathol 2017; 125: 128-137.

Wurtz A, Chambon JP, Millaire A, et al. Pericardioscopy: techniques, indications and results. Apropos of an experience with 70 cases. Ann Chir 1992; 46: 188-193.

Adebibe M, Jarral OA, Shipolini AR, et al. Does video-assisted mediastinoscopy have a better lymph node yield and safety profile than conventional mediastinoscopy? Interact Cardiovasc Thorac Surg 2012; 14: 316-319.

Wei B, Bryant AS, Minnich DJ, et al. The safety and efficacy of mediastinoscopy when performed by general thoracic surgeons. Ann Thorac Surg 2014; 97: 1878-1883.

Sayar A, Citak N, Metin M, et al. Comparison of video-assisted mediastinoscopy and video-assisted mediastinoscopic lymphadenectomy for lung cancer. Gen Thorac Cardiovasc Surg 2011; 59: 793-798.

Anraku M, Miyata R, Compeau C, et al. Video-assisted mediastinoscopy compared with conventional mediastinoscopy: are we doing better? Ann Thorac Surg 2010; 89: 1577-1581.

Leschber G, Sperling D, Klemm W, et al. Does video-mediastinoscopy improve the results of conventional mediastinoscopy? Eur J Cardiothorac Surg 2008; 33: 289-293.

Kimura $\mathrm{H}$, Yasufuku K, Ando S, et al. Indications for mediastinoscopy and comparison of lymph node dissections in candidates for lung cancer surgery. Lung Cancer 2007; 56: 349-355.

Venissac N, Alifano M, Mouroux J. Video-assisted mediastinoscopy: experience from 240 consecutive cases. Ann Thorac Surg 2003; 76: 208-212.

Witte B, Wolf M, Hillebrand H, et al. Extended cervical mediastinoscopy revisited. Eur J Cardiothorac Surg 2014; 45: 114-119.

Obiols C, Call S, Rami-Porta R, et al. Extended cervical mediastinoscopy: mature results of a clinical protocol for staging bronchogenic carcinoma of the left lung. Eur J Cardiothorac Surg 2012; 41: 1043-1046.

Metin C, Citak N, Sayar A, et al. The role of extended cervical mediastinoscopy in staging of non-small cell lung cancer of the left lung and a comparison with integrated positron emission tomography and computed tomography: does integrated positron emission tomography and computed tomography reduce the need for invasive procedures? J Thorac Oncol 2011; 6: 1713-1719.

Freixinet Gilart J, García PG, de Castro FR, et al. Extended cervical mediastinoscopy in the staging of bronchogenic carcinoma. Ann Thorac Surg 2000; 70: 1641-1643. bronchogenic carcinoma of the left upper lobe. J Thorac Cardiovasc Surg 1987; 94: 673-678.

2 Dawson AG, Waller DA. Cervical mediastino-thoracoscopy. In: Zielinski M, Rami-Porta R, eds. The Transcervical Approach in Thoracic Surgery. Heidelberg, Springer, 2014; pp. 45-51.

Call S, Obiols C, Rami-Porta R, et al. Video-assisted mediastinoscopic lymphadenectomy for staging non-small cell lung caner. Ann Thorac Surg 2016; 1326-1333.

Turna A, Demirkaya A, Ozkul S, et al. Video-assisted mediastinocopic lymphadenectomy is associated with better survival than mediastinoscopy in patients with resected non-small cell lung cancer. J Thorac Cardiovasc Surg 2013; 146: 774-780.

5 Witte B, Wolf R, Hürtgen M, et al. Video-assisted mediastinoscopic surgery: clinical feasibility and accuracy of mediastinal lymph node staging. Ann Thorac Surg 2006; 82: 1821-1827.

Zielinski M. Transcervical extended mediastinal lymphadenectomy (TEMLA): the standard procedure and its variations. In: Zielinski M, Rami-Porta R, eds. The transcervical approach in thoracic surgery. Heidelberg, Springer, 2014; pp. 101-116.

Zielinski M, Hauer L, Hauer J, et al. Transcervical Extended Mediastinal Lymphadenectomy (TEMLA) for staging non-small-cell lung cancer (NSCLC). Pneumonol Alergol Pol 2011; 79: 196-206. 
118 Explanatory notes - Specific anatonical sites. In: Wittekind Ch, Compton CC, Brierley J, Sobin LH, eds. UICC TNM Supplement on Uniform Use. 4th Edn. Oxford, Wiley-Blackwell, 2012; p. 70.

119 Martini N, Ginsberg RJ. Surgical management. In: Pearson FG, Deslauriers J, Ginsberg RJ, Hiebert CA, McKneally MF, Urshel Jr HC, eds. Thoracic Surgery. New York, Churchill Livingstone, 1995; pp. 690-705.

120 Goldstraw P. Report on the International workshop on intrathoracic staging, London, October 1996. Lung Cancer 1997; 18: 107-111.

121 Site-specific requirements of $\mathrm{pT}$ and $\mathrm{pN}$. In: Wittekind Ch, Compton CC, Brierley J, Sobin LH, eds. UICC TNM Supplement on Uniform Use. 4th Edn. Oxford, Wiley-Blackwell, 2012; pp. 149-150.

122 Naruke T, Tsuchiya R, Kondo $\mathrm{H}$, et al. Lymph node sampling in lung cancer: how should itbe done? Eur J Cardiothorac Surg 1999; 16: Suppl. 1, 17-24.

123 Ichinose $\mathrm{Y}$, Kato H, Koike T, et al. Completely resected stage IIIA non-small cell lung cancer: the significance of primary tumor location and N2 station. J Thorac Cardiovasc Surg 2001; 122: 803-808.

124 Rami-Porta R, Wittekind Ch, Goldstraw P, et al. Complete resection in lung cancer surgery: proposed definition. Lung Cancer 2005; 49: 25-33.

125 Gagliasso M, Magliaretti G, Ardissone F. Assessing the prognostic impact of the International Association for the Study of Lung Cancer proposed definitions of complete, uncertain, and incomplete resection in non-small cell lung cancer surgery. Lung Cancer 2017; 111: 124-130.

126 Treasure T. Videothoracoscopic resection for lung cancer: moving towards a 'standard of care'. $J$ Thorac Dis 2016; 8: E772-E774.

127 Liu C-C, Shih C-H, Pennarun N, et al. Transition from a multiport technique to a single-port technique for lung cancer surgery: is lymph node dissection inferior using the single-port technique? Eur J Cardiothorac Surg 2016; 49: i64-i72.

128 Yang R, Jiao W, Zhao Y, et al. Lymph node evaluation in totally thoracoscopic lobectomy with two-port for clinical early-stage nonsmall-cell lung cancer: single-center experience of 1086 cases. Indian J Cancer 2015; 52: Suppl. 2, e134-e139.

129 Liu C, $\mathrm{Pu} \mathrm{Q}$, Guo $\mathrm{C}$, et al. Non-grasping en bloc mediastinal lymph node dissection for video-assisted thoracoscopic lung cancer surgery. BMC Surgery 2015; 15: 38.

130 Wang G-S, Wang Z, Wang J, et al. Uniportal video-assisted thoracoscopic lobectomy with systematic lymphadenectomy. J Thorac Dis 2014; 6: 1011-1016.

131 Toker A, Özyurtkan MO, Demirhan Ö, et al. Lymph node dissection in surgery for lung cancer: comparison of open vs. video-assisted vs. robotic-assisted approaches. Ann Thorac Cardiovasc Surg 2016; 22: 284-290.

132 Darling GE, Allen MS, Decker PA, et al. Randomized trial of mediastinal lymph node sampling versus complete lymphadenectomy during pulmonary resection in the patients with N0 or N1 (less than hilar) non-small cell carcinoma: Results of the American College of Surgery Oncology Group Z0030 trial. J Thorac Cardiovasc Surg 2011; 141: 662-670.

133 Darling GE, Allen MS, Decker PA, et al. Number of lymph nodes harvested from a mediastinal lymphadenectomy. Results of the randomized, prospective American College of Surgeons Oncology Group Z0030 trial. Chest 2011; 130: 1124-1129.

134 Maniwa T, Okumura T, Isaka M, et al. Recurrence of mediastinal node cancer after lobe-specific systematic nodal dissection for non-small cell lung cancer. Eur J Cardiothorac Surg 2013; 44: e59-e64.

135 Rusch VW, Crowley J, Giroux DJ, et al. The IASLC lung cancer staging project: proposals for the revision of the $\mathrm{N}$ descriptors in the forthcoming seventh edition of the TNM classifications for lung cancer. $J$ Thorac Oncol 2007; 2: 603-612.

136 Tamura M, Matsumoto I, Saito D, et al. Lymph node ratio as a prognostic factor in patients with pathological N2 non-small cell lung cancer. World J Surg Oncol 2016; 14: 295.

137 Allen MS, Darling GE, Pechet TT, et al. Morbidity and mortality of major pulmonary resections in patients with early-stage lung cancer: initial results of the randomized, prospective ACOSOG Z0030 trial. Ann Thorac Surg 2006; 81: 1013-1019.

138 Huang X, Wang J, Chen Q, et al. Mediastinal lymph node dissection versus mediastinal lymph node sampling for early stage non-small cell lung cancer: a systematic review and meta-analysis. PLoS ONE 2014; 9: e109979.

139 Riquet M, Rivera C, Pricopi C, et al. Is the lymphatic drainage of lung cancer lobe-specific? A surgical appraisal. Eur J Cardiothorac Surg 2015; 47: 543-549.

140 Riquet M, Pricopi C, Arame A, et al. From anatomy to lung cancer: questioning lobe-specific mediastinal lymphadenectomy reliability. J Thorac Dis 2016; 8: 2387-2390.

141 Riquet M, Pricopi C, Legras A, et al. Can mathematics replace anatomy to establish recommendations in lung cancer surgery? J Thorac Dis 2017; 9: E327-E332.

142 Sun Y, Gao W, Zheng H, et al. Mediastinal lymph-nodes metastasis beyond the lobe-specific. An independent risk factors towards worse prognoses. Ann Thorac Cardiovasc Surg 2014; 20: 284-291.

143 Aokage K, Yoshida J, Ishii G, et al. The impact on survival of positive intraoperative pleural lavage cytology in patients with non-small-cell lung cancer. J Thorac Cardiovasc Surg 2010; 139: 1246-1252.

144 Kaneda M, Yokoi K, Ito S, et al. The value of pleural lavage cytology examined during surgery for primary lung cancer. Eur J Cardiothorac Surg 2012; 41: 1335-1341.

145 Kameyama K, Okumura N, Miyaoka E, et al. Prognostic value of intraoperative pleural lavage cytology for non-small cell lung cancer: the influence of positive pleural lavage cytology results on T classification. $J$ Thorac Cardiovasc Surg 2014; 148: 2659-2664

146 Yanagawa N, Shiono S, Abiko M, et al. Positive intraoperative pleural lavage cytology is a predictive marker of disease recurrence in stage I lung adenocarcinoma. Interact Cardiovasc Thorac Surg 2014; 18: 621-625.

147 Nakao M, Hoshi R, Ishikawa Y, et al. Prognosis of non-small-cell lung cancer patients with positive pleural lavage cytology. Interact Cardiovasc Thorac Surg 2015; 20: 777-782.

148 Hokka D, Uchino K, Tane K, et al. Pleural lavage cytology as an independent prognostic factor in non-small-cell lung cancer patients with stage I disease and adenocarcinoma. Mol Clin Oncol 2015; 3: 244-248.

149 Shimoji M, Nishino M, Sesumi Y, et al. Prognostic impact of pleural lavage cytology in patients with primary lung cancer. Lung Cancer 2016; 102: 60-64. 
150 Shoji F, Yamazaki K, Kouso H, et al. The impact of pleural lavage cytology both before and after lung resection on recurrence of non-small cell lung cancer. Ann Thorac Surg 2016; 101: 2141-2146.

151 International Pleural Lavage Cytology Collaboratiors. Impact of positive pleural lavage cytology on survival in patients having lung resection for non-small cell lung cancer: An international individual patient data meta-analysis. J Thorac Cardiovasc Surg 2010; 139: 1441-1446.

152 Saso S, Rao C, Ashrafian H, et al. Positive pre-resection pleural lavage cytology is associated with increased risk of lung cancer recurrence in patients undergoing surgical resection: a meta-analysis of 4450 patients. Thorax 2012; 67: 526-532.

153 Wang C-M, Ling Z-G, Wu Y-B, et al. Prognostic value of pleural lavage cytology in patients with lung cancer resection: An updated meta-analysis. PLoS ONE 2016; 11: e0157518.

154 Girard N, Deshpande C, Lau C, et al. Comprehensive histologic assessment helps to differentiate multiple lung primary nonsmall cell carcinomas from metastases. Am J Surg Pathol 2009; 33: 1752-1764.

155 Travis WD, Brambilla E, Rami-Porta R, et al. Visceral pleural invasion: pathologic criteria and use of elastic stains: proposal for the 7th edition of the TNM classification for lung cancer. J Thorac Oncol 2008; 3: 1384-1390.

156 Kadota K, Villena-Vargas J, Yoshizawa A, et al. Prognostic significance of adenocarcinoma in situ, minimally invasive adenocarcinoma, and nonmucinous lepidic predominant invasive adenocarcinoma of the lung in patients with stage I disease. Am J Surg Pathol 2014; 38: 448-460.

157 Yoshizawa A, Motoi N, Riely GJ, et al. Impact of proposed IASLC/ATS/ERS classification of lung adenocarcinoma: prognostic subgroups and implications for further revision of staging based on analysis of 514 stage I cases. Modern Path 2011; 24: 653-664.

158 Suzuki S, Sakurai H, Masai K, et al. A proposal for definition of minimally invasive adenocarcinoma of the lung regardless of tumor size. Ann Thorac Surg 2017; 104: 1027-1032. 